\title{
Organic Chemistry of the Metals
}

\begin{abstract}
A
DISCUSSION on recent advances in the organic chemistry of the metals, which had special reference to the transitional metals, was held in Section B (Chemistry) during the Cambridge meeting of the British Association. It was opened by Dr. F. G. Mann, who said that recent advances in the organic chemistry of the metals are so numerous and cover so wide a field that any attempt to deal com. prehensively with them in the brief time available would become a mere catalogue of individual in. vestigations. The most important advance, which in his opinion was the investigations (mainly by Hans Fischer and his co-workers) into the structure and synthesis of the porphyrins, was, however, too specialized and too complicated for suitable treatment on that occasion; he therefore limited his own contribution to an account of certain polynuclear metallic compounds, since this work was largely carried out in Cambridge, and its discussion, which followed logically from Prof. C. S. Gibson's presidential address to Section B, involved certain questions of chemical linkage which are of fundamental and therefore general interest.

It has been known for many years that when spongy platinum and phosphorus pentachloride are heated in a sealed tube, two compounds, of empirical formulæ $\left(\mathrm{PCl}_{3}\right)_{2} \mathrm{PtCl}_{2}$ and $\mathrm{PCl}_{3} \mathrm{PtCl}_{2}$ respectively, are formed. These compounds when treated with an aliphatic alcohol ROH give the corresponding ester derivatives $\left\{(\mathrm{RO})_{3} \mathbf{P}\right\}_{2} \mathrm{PtCl}_{2}$ and $(\mathrm{RO})_{3} \mathrm{PPtCl}_{2}$. Molecular weight determinations on the latter compound show, however, that it has the molecular formula $\left[(\mathrm{RO})_{3} \mathrm{PPtCl}_{2}\right]_{2}$, and Werner suggested in 1909 that the parent compound had the structure (I) or (II). Similar results have been obtained with the corresponding palladium derivatives.
\end{abstract}

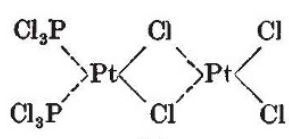

(I)<smiles></smiles>

(II)
Decisive evidence for this 'bridged' linkage of metallic atoms through acid radicals has, however, only recently been obtained, when its existence in gold compounds was proved by Gibson and Powell (cf. the sectional presidential address) and in palladium compounds by Mann, Purdie and Wells.

The non-ionic derivatives of the tertiary phosphines and arsines with palladium dichloride, of general formulæ $\left[\left(\mathrm{R}_{3} \mathrm{P}\right)_{2} \mathrm{PdCl}{ }_{2}\right]$ and $\left[\left(\mathrm{R}_{3} \mathrm{As}\right)_{2} \mathrm{PdCl}_{2}\right]$, were known to have the trans uniplanar configuration. Mann and Purdie showed that these compounds in hot alcoholic solution readily react with ammonium palladochloride giving derivatives, for example, 2 $\left[\left(\mathrm{R}_{3} \mathrm{P}\right) \mathrm{PdCl}_{2}\right]_{2}$, similar to (I) and (II). These 'bimolecular'derivatives should theoretically exist in three

$$
\begin{aligned}
& {\left[\left(\mathbf{R}_{3} \mathbf{P}\right)_{2} \mathrm{PdCl}_{2}\right]+\left(\mathrm{NH}_{4}\right)_{2}\left[\mathrm{PdCl}_{4}\right]=} \\
& {\left[\left(\mathrm{R}_{3} \mathrm{P}\right) \mathrm{PdCl}_{2}\right]_{2}+2 \mathrm{NH}_{4} \mathrm{Cl}}
\end{aligned}
$$

forms, the unsymmetrical form (III) and the cis and trans symmetrical forms (IV) and (V). In the crystalline state they occur in only one form, which is the same in both the phosphine and arsine series, since the corresponding members in the two series are iso. morphous. This form has been shown by Mann and Wells to be the trans symmetric form (V).

There is abundant evidence, however, that these compounds in organic solvents give a tautomeric mixture of the three forms (III), (IV) and (V). This is shown partly by their anomalous dipole moments,

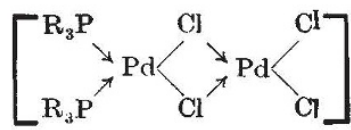

(III)

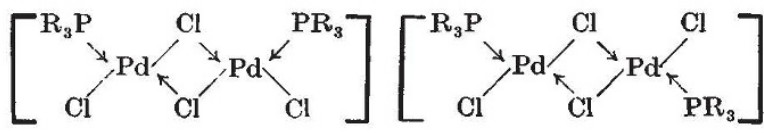

(Iv)

which have been measured by Dr. Finn at Oxford, and partly by their chemical reactions. Thus strong evidence in favour of the unsymmetric form (III) is provided by $\alpha \alpha^{\prime}$-dipyridyl (symbolized by 'dpy'), which splits the phosphine compound thus :

$$
\begin{aligned}
& {\left[\left(\mathrm{R}_{3} \mathrm{P}\right)_{2} \mathrm{PdCl}_{2} \mathrm{PdCl}_{2}\right]+\mathrm{dpy}=} \\
& {\left[\left(\mathrm{R}_{3} \mathrm{P}\right)_{2} \mathrm{PdCl} l_{2}\right]+\left[\mathrm{dpy} \mathrm{PdCl}_{2}\right]}
\end{aligned}
$$

Moreover, the dichloro-oxalate, which presumably has also the unsymmetric structure, gives a similar reaction :

$$
\begin{aligned}
& {\left[\left(\mathrm{R}_{3} \mathrm{P}\right)_{2} \mathrm{PdCl}_{2} \mathrm{PdC}_{2} \mathrm{O}_{4}\right]+\mathrm{dpy}=} \\
& {\left[\left(\mathrm{R}_{3} \mathrm{P}\right)_{2} \mathrm{PdCl} l_{2}\right]+\left[\mathrm{dpy} \mathrm{PdC}_{2} \mathrm{O}_{4}\right]}
\end{aligned}
$$

On the other hand, a monacid base such as $p$-toluidine (represented as B) splits the compound in its symmetric form :

$$
\left[\left(\mathrm{R}_{3} \mathrm{P}\right) \mathrm{ClPdCl}_{2} \mathrm{PdCl}\left(\mathrm{PR}_{3}\right)\right]+2 \mathrm{~B}=2\left[\left(\mathrm{R}_{3} \mathrm{P}\right)(\mathrm{B}) \mathrm{PdCl}_{2}\right]
$$

The formation of this equilibrium from the homogeneous crystalline compound shows that the unbridged groups in these molecules must readily interchange their positions. This mobility is not, however, limited to the unbridged groups. Chatt and Mann recently showed that the trichloro-monomercapto derivative (VI) in organic solvents readily produces an equilibrium with the dichloro-dimercapto derivative (VII) and the tetrachloro-com pound (V). Hence the bridging groups also possess considerable mobility.

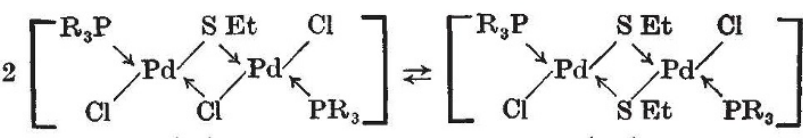
(vI) (vII)<smiles>[R12]C1CC[R17](Cl)(Cl)[Y17]1(Cl)[Y17]CC</smiles>

(v) 
Prof. N. V. Sidgwick had pointed out that the symmetric forms (IV) and (V) differ from the unsymmetric form (III) inasmuch as they possess the ring<smiles></smiles>

(vIII)

(VIII) and might be expected to have greater stability than the unsymmetric form (III). The chelated di-sulphide and di-arsine compounds (IX), (X) and (XI) have consequently been prepared by Chatt and Mann. If<smiles>[R]S[Y12](=S)Cl</smiles>

(Ix)<smiles>[R16][Y16]1([R16])CCCC1Cl</smiles>

(x)

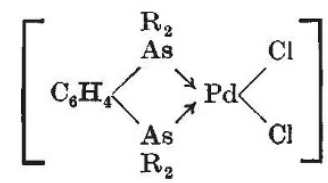

(XI)

these compounds reacted with ammonium palladochloride, the resulting 'bridged' compounds must have the unsymmetric structure of type (III). Actually no 'bridged' derivatives were obtained from these three compounds, and it appears therefore that the unsymmetric compounds are too unstable to exist in the solid state. On the other hand, Mellor, Burrows and Morris prepared two isomeric cuprocupric compounds, of formula $\left[\left(\mathrm{R}_{3} \mathrm{As}\right)_{3} \mathrm{Cu}_{2} \mathrm{Cl}_{3}\right]$, and suggested that these isomerides have the

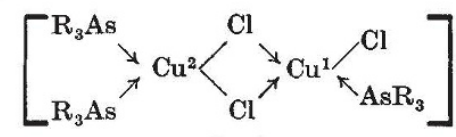

(xII)

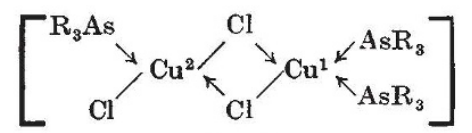

(XIII)

constitutions (XII) and (XIII), the cuprous and the cupric complexes having the tetrahedral and the uniplanar configuration respectively. The former compound possesses a ring structure electronically similar to that in (III), and decisive evidence for the structure of these isomerides would be of great interest. Reference was also made to the cuprous and argentous compounds $\left[\mathrm{R}_{3} \mathrm{As} \rightarrow \mathrm{CuI}\right]_{4}$ and $\left[\mathrm{R}_{3} \mathrm{As} \rightarrow \mathrm{AgI}\right]_{4}$ investigated by Mann, Wells and Purdie.

Prof. L. O. Brockway pointed out that investigations of the structure of organic derivatives of the noble metals now afford definite information with regard to the number and length of the bonds by which the metallic atom is linked to other groups, as well as the characteristic inter-bond angles; the number of such bonds is $2,4,5$ or 6 in the compounds of various metals. The 4-covalent metals in the copper and nickel groups have a planar configuration in the divalent state (for example, the above palladium compounds, the cupric and argentic picolinates, and the nickel, palladium and platinum aldoxime derivatives) and a tetrahedral configuration in other valency states (for example, $\left[\mathrm{Cu}\left(\mathrm{CH}_{3} \mathrm{CSNH}_{2}\right)_{4}\right] \mathrm{Cl}$, $\left.\mathrm{Ni}(\mathrm{CO})_{4},\left(\mathrm{CH}_{3}\right)_{3} \mathrm{PtCl}\right)$. The 2-covalent metallic complexes have a linear configuration (for example, $\left[\mathrm{Ag}(\mathrm{CN})_{2}\right]$ ), the 5-covalent a trigonal bipyramid (for example, $\left.\mathrm{Fe}(\mathrm{CO})_{5}\right)$ and the 6-covalent an octahedral configuration. He emphasized, however, that the work of Mann and Wells on the bridged palladium compounds shows that the co-ordinate and covalent links (as represented in the above formulæ) are identical in length, and that it is impossible to make a clear distinction between these links in complex metallic compounds. As an example of the variation of bond length with the number of bonds per atom, he cited the series $\mathrm{Ni}(\mathrm{CO})_{4}, \mathrm{Co}(\mathrm{NO})(\mathrm{CO})_{3}$, $\mathrm{Fe}(\mathrm{NO})_{2}(\mathrm{CO})_{2}, \mathrm{Cr}(\mathrm{CO})_{5}$. The metallic atoms in these compounds are isoelectronic, but whereas the observed bond-length to carbon in the first three compounds is 1.82-1.84 A., in the fourth compound it is $1.91 \mathrm{~A}$.

A very interesting example of the application of complex metallic compounds to the study of nuclear physics was given in a preliminary announcement by Dr. B. C. Saunders. Dr. Goldhaber and he have used the non-ionic cupric derivative of ethyl aceto-acetate to effect the separation of the active isotope of copper $\left({ }_{29}^{64} \mathrm{Cu}\right)$. The copper aceto-acetate is irradiated by slow neutrons and its activity measured : it is then dissolved in chloroform and shaken with aqueous copper acetate. Some of the active isotope is thus transferred to the aqueous solution, from which it is precipitated by zine, and its activity is measured. The chloroform layer gives copper acetoacetate of much reduced activity. F. G. MANN.

\section{Recent Research in Seismology}

$\mathrm{U}$ NDER the chairmanship of Dr. C. G. Darwin in the morning, and of Mr. R. S. Whipple in the afternoon of August 23, a symposium on seismology covering a very wide field of topics was held at Cambridge in Section A (Mathematics and Physical Sciences) of the British Association. At the outset, a very warm tribute was paid by Dr. F. J. W. Whipple to the pioneer work of Dr. C. Davison, who was the secretary of the earth tremors committee in 1895 , when Prof. John Milne returned to England from Japan. The work of these and others has led on to the present work on the International Seismological
Summary, now being carried on by Miss E. F. Bellamy and Mr. J. S. Hughes. There are now 439 observatories in the northern hemisphere and 59 in the southern hemisphere sending seismological readings to Oxford, from which it has been possible to locate 2,865 different epicentres between 1913 and 1935. It is hoped that more stations will be initiated in the southern hemisphere, especially in South America and South Africa.

In pure seismology, the discussion was continued by Miss I. Lehmann of Copenhagen, who described and explained the characteristic seismograms obtained 